\title{
Uncertainty Approval of Gear Ring Radial Runout in Image Measurement
}

\author{
Yaodong $\mathrm{Xu}$ \\ Manufacturing Engineering Department, Shanghai University of Engineering Science, Shanghai, 200437, China
}

\begin{abstract}
To resolve the extra workload of spindles' preparation, image measurement method was applied in various part measurement of geared ring radial runout without spindles. An experiment was made to explore the errors and uncertainty of gear measurement through image measurement .By analysis of data, the systematic error was found and eliminated from it. The approval of $A$ series uncertainty and $B$ series uncertainty were done as well as range control chart in statistic control, which got the same result in the approval of gear precision.By applying image measurement, various gear ring radial runout can be measured.
\end{abstract}

Keywords-image measurement; gear ring radial runout; uncertainty; error correction; range control

\section{INTRODUCTION}

The radial runout of the gear ring is the maximum variation of the distance between pitch circle and the axis which is mainly used to evaluate the radial error caused by the geometric eccentricity of the gear. The gear ring runout will influence the accuracy of the gear transmission. It is one of the indexes to evaluate the accuracy of gears[1].

Gear ring radial runout is commonly measured by contact method with special instruments, adopting installation of gear spindle and core clampers. Select the appropriate probe placement in the alveolar, generally measured head diameter was 1.68 times gear modulus [2].The accuracy of contact measurement relies on the manufacturing precision of the spindle, the installation accuracy of the spindle and gear ,so that the coaxiality is much required [3].

Along with the development of optical imaging technology and computer software technology, machine vision image measurement began to be widely used[4]. Image measurement in the measurement of small modulus gear and poor rigidity gear will play a great advantage.

\section{GEAR RADIAL RUNOUt ERROR DETECTION}

In image measurement the gear position should be adjusted, so that the measured gear axis and the rotary table axes, and the cross line center projection will be coaxial. According to the gear modulus $\mathrm{m}$ and tooth number $\mathrm{z}$, the gear pitch circle diameter $d$ was calculated.The origin of reticle coordinate along the $X$ axis orientation moves to the $d / 2$ position, rotating the rotary worktable, the reticle line origin in the gear profile, as shown in Figure 1. The digital reading was cleared, marking the first time a reading of 0 . On the gear radial runout measurement the gear is usually divided into 8 parts, which is calculated by $z / 8$ in each angle of rotation, and origin of the reticle again was moved to the gear contour line, and the reading is the first measurement data of gear radial. Then turn 7 times, a total of 8 . The gear radial runout $F_{r}$ was finally gained equal to the range of the maximum and the minimum values of the readings.

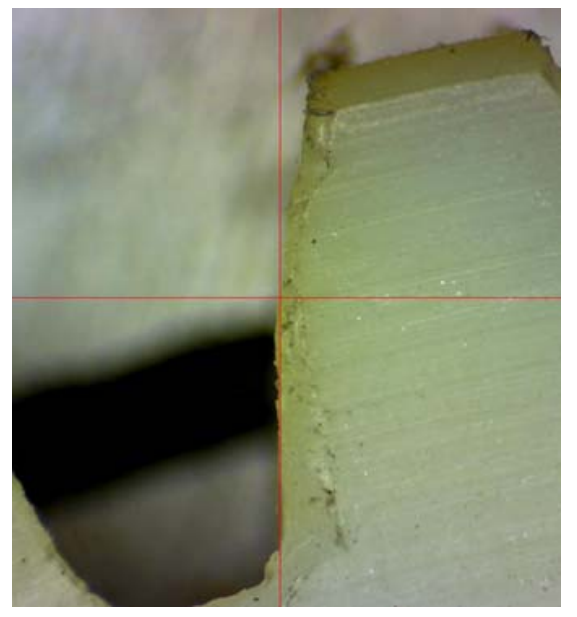

FIGURE I. CENTER OF CROSS LINE ON GEAR CONTOUR

Test of plastic gear modulus $\mathrm{m}=3 \mathrm{~mm}$, tooth number $\mathrm{z}=41$.In experiment, every time the worktable will rotate 5 tooth angle which is integer value of 41 divided by 8 . that is about $\frac{360}{Z} \times 5=\frac{360}{41} \times 5=43.9^{\circ}$, in fact $44^{\circ}$ minus $6^{\prime}$ '. The known worktable worm rotation is 4 degrees, namely each measurement, the need to rotate table 11 laps and then reverse minus $6{ }^{\prime}$.

\section{A. Test Data Record}

The gear is rotated for 2 laps, and two tests were done, and the test data were recorded as shown in Table 1 and table 2.

\section{B. Test Data Analysis}

The two measurements of a total of 16 data, through the line chart to analyze, and add the trend line, as shown in Figure 2.

Through statistical analysis of the 16 data, the results of the measurement are $X=\bar{X} \pm 3 s=61.862 \pm 0.903 \mathrm{~mm}$.The system error of the measurement of the gear radial runout is the difference between the average value and the true value of the measured data[5].Error of the system includes personnel measurement error of habituation,worm gear and worm return 
drive gap error,gear coaxiality error with center of cross line and rotary table.

TABLE I. MEASUREMENT DATA OF GEAR ROTATION IN 1ST LAP

\begin{tabular}{|l|c|c|c|c|c|c|c|c|}
\hline Measurement No. & 1 & 2 & 3 & 4 & 5 & 6 & 7 & 8 \\
\hline Measurement value $X$ & 61.500 & 61.500 & 61.585 & 62.020 & 62.020 & 62.020 & 61.900 & 61.855 \\
\hline $\begin{array}{l}\text { Gear radial runout } \\
\text { error } F_{r}\end{array}$ & $F_{r}=X_{\max }-X_{\min }=62.020-61.500=520 \mu \mathrm{m}$ \\
\hline
\end{tabular}

TABLE II. MEASUREMENT DATA OF GEAR ROTATION IN 2ND LAP

\begin{tabular}{|l|c|c|c|c|c|c|c|c|}
\hline Measurement No. & 1 & 2 & 3 & 4 & 5 & 6 & 7 & 8 \\
\hline Measurement value $X$ & 61.570 & 61.440 & 61.610 & 61.955 & 62.280 & 62.470 & 61.995 & 62.070 \\
\hline $\begin{array}{l}\text { Gear radial runout } \\
\text { error } F_{r}\end{array}$ & $F_{r}=X_{\max }-X_{\min }=62.470-61.440=1030 \mu \mathrm{m}$ \\
\hline
\end{tabular}

According to the analysis of Figure 2, the 1st and 2nd measured radial runout error are $520 \mu \mathrm{m}, 1030 \mu \mathrm{m}$. The first error is less than second times, through the linear trend analysis, the error increased. The gear runout presents periodic changes, such as polynomial trend line shown. It can be analyzed that because of the worm drive, there is the return gap. Each rotation of 11 laps, 44 degrees, and the reverse rotation of 6 ', will cause the change of the actual readings on the hand wheel but the rotary table does not move, so with the increase of frequency measurement, the measurement error has an increasing trend.Otherwise, the center of rotary table, gear and cross line may have coaxial error, due to eccentricity, resulting in near point and far point difference of gear rotation process, and in the figure shows periodic change.

Actually coaxiality error of cross line and rotary table can be control in less than or equal to $40 \mu \mathrm{m}$. According to the trend line shown, worm return clearance error in one test is equal to $(62.1-61.6) / 2=0.250 \mathrm{~mm}=250 \mu \mathrm{m}$.

By measuring, the gear radial runout error in 1st measuring is $520 \mu \mathrm{m}$, the actual gear radial runout error should be of $520 \mu \mathrm{m}$ minus the coaxiality error of worm and worm wheel return clearance error. By adjusting the error, the actual gear radial runout error in 1 st measuring is $F_{r}=520-40-250=230 \mu \mathrm{m}$,in 2nd measuring is $F_{r}=1030-40-250=740 \mu \mathrm{m}$.

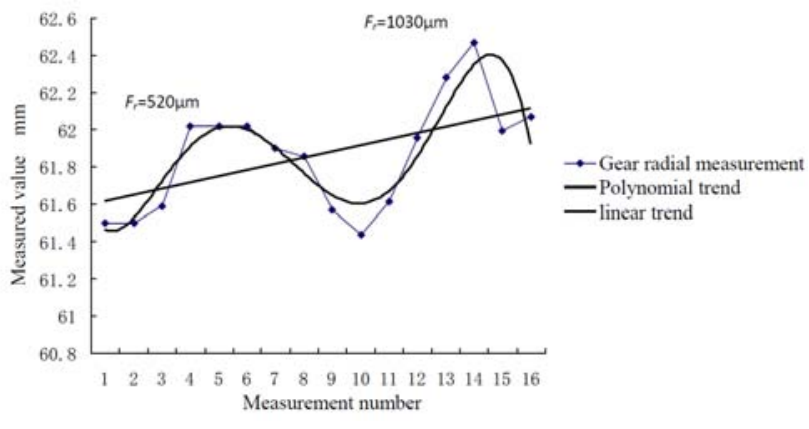

FIGURE II. ANALYSIS OF THE RADIAL RUNOUT OF GEAR RING

\section{UNCERTAINTY APPROVAL}

Gear radial runout measurement errors include gear installed eccentric error, worm return gap error, the dividing error of worm gear and instruments shown value error and repeated measurement error[6]. And among these errors, gear installed eccentric error and worm return gap error have some regulations, belonging to the system error, which can be eliminated in results. The dividing error of worm gear, the instruments shown value error and repeated measurement error

\section{A. Systematic Error}

In the experiment,the systematic error may include gear installed eccentric error $\delta_{1}$ and worm return gap error $\delta_{2}$. The coaxiality error of the cross line and the rotary table can be controlled under $40 \mu \mathrm{m}$.So the gear eccentric error $\delta_{1}=40 \mu \mathrm{m}$. According to the trend line shown, worm return gap error in $1 \mathrm{st}$ experiment is $\delta_{2}=(62.1-61.6) / 2=0.250 \mathrm{~mm}=250 \mu \mathrm{m}$. Combining the above two kinds of errors, the system error is $40+250=290 \mu \mathrm{m}$,Error correction constant $C=-290 \mu \mathrm{m}$

\section{B. B Series Uncertainty}

B series uncertainty can be approved by dividing error of worm gear $\delta_{3}$ and instruments shown value error $\delta_{4}$. It is known worm gear indexing error has the following formula.

$$
\delta_{3}=\frac{r_{b} \cdot \Delta \varphi_{x}}{\sin \alpha},
$$

In the formula, $\Delta \varphi_{x}$ is manufacturing error of rotary table, about \pm 30 " $( \pm 0.000145 \mathrm{rad}) . r_{b}$ is radius of base circle, $\alpha$ is the pressure angle of the gear dividing circle,about $20^{\circ}$.Through calculation, $\delta_{3}=25 \mu \mathrm{m}$.

According to the data by measuring instrument of division to obey the principle of average distribution [7], the standard uncertainty of the worm gear is $u_{1}=\frac{25}{\sqrt{3}}$.

In the experiment, the resolution of the image measuring instrument is $\pm 5 \mu \mathrm{m}$, so the measurement error of the instrument is $\delta_{4}= \pm 5 \mu \mathrm{m}$. According to the shown data of the instrument in the index value to obey the principle of average distribution of [8].The standard uncertainty of the shown error is $u_{2}=\frac{5}{\sqrt{3}}$. 


\section{A Series Uncertainty}

Gear radial runout of repeated measurements will produce A series uncertainty which can be evaluated by standard deviation in single value measurement. According to JJF 1059-1999 ,under repeatable conditions, independent observations of $X_{i}$ for $n$ times, the experimental standard deviation $S\left(X_{i}\right)$ for single measurement results can be approximate evaluated as follow, when the number of measurements is small[9], $\mathrm{R}$ is the range of the data .Range coefficient $C$ and degree of freedom $V$ are shown in Table 3.

$$
s\left(X_{i}\right)=R / C=u\left(X_{i}\right),
$$

TABLE III.RANGE COEFFICIENT $C$ AND DEGREE OF FREEDOM $V$

\begin{tabular}{|c|c|c|c|c|c|c|c|c|}
\hline$N$ & 2 & 3 & 4 & 5 & 6 & 7 & 8 & 9 \\
\hline$C$ & 1.13 & 1.64 & 2.06 & 2.33 & 2.53 & 2.70 & 2.85 & 2.97 \\
\hline$v$ & 0.9 & 1.8 & 2.7 & 3.6 & 4.5 & 5.3 & 6.0 & 6.8 \\
\hline
\end{tabular}

According to the data on the table 3, when the number of measurements $N=8$, the coefficient of $C=2.85$, the degree of freedom $v=6.0$. So has the follow.

The standard deviation of 1 st independent measurement is as follow.

$$
s_{1}=\frac{R_{1}}{C_{1}}
$$

The standard deviation of 2 nd independent measurement is as follow.

$$
s_{2}=\frac{R_{2}}{C_{2}}
$$

Synthetic standard deviation is as follow.

$$
s^{2}=\frac{s_{1}^{2} v_{1}+s_{2}^{2} v_{2}}{v_{1}+v_{2}}
$$

As known $R_{1}=230, \quad R_{2}=740, C_{1}=C_{2}=2.85$, $v_{1}=v_{2}=6.0$, it can be calculated that $s=191 \mu \mathrm{m}$, and A series standard uncertainty $u_{3}=s=191 \mu \mathrm{m}$.So the synthetic standard uncertainty $u$ can be calculated as follow.

$$
u=\sqrt{u_{1}^{2}+u_{2}^{2}+u_{3}^{2}}=\sqrt{\frac{25^{2}}{3}+\frac{5^{2}}{3}+191^{2}} \approx 192 \mu \mathrm{m}
$$

\section{Expanded Uncertainty $U_{95}$}

Because of the measurement process is random, to express the measurement results, take most times contain factor $k_{95}=2$, the expanded uncertainty $U_{95}= \pm k_{95} \cdot u= \pm 2 u= \pm 384 \mu \mathrm{m}$, confidence probability $p=95 \%$.

$$
\begin{gathered}
\text { Gear radial runout measurement results } \\
F_{r}=\frac{230+740}{2} \pm 384 \mu \mathrm{m}=(485 \pm 384) \mu \mathrm{m}\left(k_{95}=2, \quad p=0.95\right) .
\end{gathered}
$$

\section{RANGE StATISTICAL CONTROL}

Gear radial runout error reflects the difference of maximum value and minimum value. According to two independent measurement data, as table 4 shows, these two groups of data

\begin{tabular}{|c|c|c|c|c|c|c|c|c|c|}
\hline \multirow{2}{*}{ Sample No } & \multicolumn{8}{|c|}{ Measured data } & \multirow{2}{*}{$\begin{array}{c}\text { Range } R \\
(+ \text { Correction } C)\end{array}$} \\
\hline & $X_{1}$ & $X_{2}$ & $X_{3}$ & $X_{4}$ & $X_{5}$ & $X_{6}$ & $X_{7}$ & $X_{8}$ & \\
\hline 1 & 61.500 & 61.500 & 61.585 & 62.020 & 62.020 & 62.020 & 61.900 & 61.855 & 0.230 \\
\hline 2 & 61.570 & 61.440 & 61.610 & 61.955 & 62.280 & 62.470 & 61.995 & 62.070 & 0.740 \\
\hline & & & & & & & & & $\bar{R}=0.485$ \\
\hline
\end{tabular}
can be considered as two samples in the extraction of the overall. And gear radial runout is actually the range of samples. Application of statistical process control method [10], range analysis of the two groups of data is as follows. System error correction value of $C$ is $-290 \mu \mathrm{m}$.

TABLE IV. STATISTICAL DATA OF SAMPLE RANGE UNIT (MM)

The statistical properties of the $\mathrm{R}$ control chart are available as follow.

Central line $C L=\bar{R}=0.485 \mathrm{~mm}=485 \mu \mathrm{m}$

Upper control limit $\quad \mathrm{UCL}=D_{4} \bar{R}=1.864 \times 485 \approx 904 \mu \mathrm{m}$

Lower control limit $\quad L C L=\mathrm{D}_{3} \bar{R}=0.136 \times 485 \approx 66 \mu \mathrm{m}$

In the formula, $D_{4} 、 D_{3}$ are the coefficients obtained from the statistical table of the control chart.

According to the analysis, measurement utmost result value evaluated by A series and B series synthetic uncertainty is $485+384=869 \mu \mathrm{m}$, is smaller than the result of $904 \mu \mathrm{m}$ from range statistical control analysis of the upper control limit which, however,is similar with the single value of standard deviation $903 \mu \mathrm{m}$. According to gear tolerance precision of $685<(869,904)<968$, the gear radial runout tolerance level is determined at level 17 by both methods. However, it is worth noting that the measured gear precision has exceeded 13 levels according to the gear precision, of which 0 is the highest, level 12 is the lowest accuracy level. The reason is that mechanical stress and temperature stress in machining process of the plastic gear leads to tooth strain at the tooth profile, causing the tooth profile of non arc and flash phenomenon, influencing tooth profile accuracy. As the tooth profile deviation is larger,the radial error of the gear is larger corresponding. 


\section{CONCLUSION}

Gear ring radial runout error of all types can be measured by image measurement method,without spindle and core clampers. Before measurement, the centers of gear ,rotary table and image cross line need to be adjusted coaxially. As the existence of the rotary eccentric error, rotary indexing error, worm return gap error and repeatability of measurement error makes system error and random error bring into the results. In order to reflect the uncertainty of measurement, the system error is corrected, and the uncertainty was assessed using A series and $\mathrm{B}$ series, also the control limits of the range were evaluated by range control chart. The results showed that two methods in evaluating the gear precision reach to the same conclusion, while the range statistical control chart method is relatively simple to calculate the error limit . Because of mechanical stress and thermal stress in machining, the plastic gear has too large tooth profile deviation, and ultimately leading to a large ring gear radial runout error.

\section{ACKNOWLEDGEMENTS}

This research was financially supported by Shanghai Municipal Education Commission key projects(BJYXX13YYYJ00) and Shanghai University experimental technology team construction plan(A2-8950-13-0706).

\section{REFERENCES}

[1] Yue-guo WANG,Xiong-pu LU.The evaluation of the uncertainty of measurement results in the gear ring radial runout[J].Measuring Technique,2009(6):68-69(in Chinese)

[2] Tai-chang ZHANG.500 Questions of Gear Measurement[M].Beijing:China Standard Press,2007(in Chinese)

[3] Jing-bin GUO,Da-sha ZHANG,Ji-cheng ZHANG, etc. Research on Compensation of the Installation Eccentricity in the Gearwheel Measurement[J].ACTA METROLOGICA SINICA,2011(2):118-122(in Chinese)

[4] Jun-cheng XU,Li-yan ZHANG,Hua YAN,etc.Small Module Plastic Gear On-Line Detection Based on Machine Vision[J].MODULAR MACHINE TOOL \& AUTOMATIC MANUFACTURING TECHNIQUE,2011(3):57-60(in Chinese)

[5] Yao-dong XU,Wei ZHENG.Nonrigid gear projecting measurement \& systematic and random error analysis[J].Optical Technique, 2010(5):744-748.(in Chinese)

[6] Gang CHEN,Lei-ming JIN.Detection appliance indication error uncertainty approval of geared ring radial runout[J].Measurement technique,2011(8):64-66. (in Chinese)

[7] Zhong-yan FANG,Yan LI.Quality engineering and measurement technology principle[M]. Beijing:Tsinghua University Press,2002:76-114. (in Chinese)

[8] Hui-ling CHEN,Zheng-yu QIAN.Experiment sieve projection measuring new method and measurement uncertainty analysis[J].Measurement Technique,2011(6):35-37. (in Chinese)

[9] National quality technology supervision bureau.JJF 1059-1999 Approval and expression about measurement uncertainty[S].Beijing:China Measurement Press, 1999. (in Chinese)

[10] Jun WAN.Manufacturing quality control methods and application[M].Beijing:Machine Industry Press, 2011. (in Chinese) 